\title{
Differentially expressed proteins in the skin mucus of Atlantic cod (Gadus morhua) upon natural infection with Vibrio anguillarum
}

Binoy Rajan, Jep Lokesh, Viswanath Kiron and Monica F Brinchmann*

\begin{abstract}
Background: Vibriosis caused by $V$. anguillarum is a commonly encountered disease in Atlantic cod farms and several studies indicate that the initiation of infection occurs after the attachment of the pathogen to the mucosal surfaces (gut, skin and gills) of fish. Therefore it is necessary to investigate the role of different mucosal components in fish upon $V$. anguillarum infection. The present study has two parts; in the first part we analyzed the differential expression of skin mucus proteins from Atlantic cod naturally infected with $V$. anguillarum using two dimensional gel electrophoresis coupled with mass spectrometry. In the second part, a separate bath challenge experiment with $V$. anguillarum was conducted to assess the mRNA levels of the genes in skin tissue, corresponding to the selected proteins identified in the first part.

Results: Comparative proteome analysis of skin mucus of cod upon natural infection with $V$. anguillarum revealed key immune relevant proteins like calpain small subunit 1, glutathione-S-transferase omega 1, proteasome $26 \mathrm{~S}$ subunit, 14-kDa apolipoprotein, beta 2-tubulin, cold inducible RNA binding protein, malate dehydrogenase 2 (mitochondrial) and type II keratin that exhibited significant differential expression. Additionally a number of protein spots which showed large variability amongst individual fish were also identified. Some of the proteins identified were mapped to the immunologically relevant JNK (c-Jun N-terminal kinases) signalling pathway that is connected to cellular events associated with pathogenesis. A bath challenge experiment with $V$. anguillarum showed differential expression of beta 2-tubulin, calpain small subunit 1, cold inducible RNA binding protein, flotillin1, and glutathione S-transferase omega 1 transcripts in the skin tissue of cod during early stages of infection.

Conclusions: Differentially expressed proteins identified in the cod skin mucus point towards their possible involvement in $V$. anguillarum pathogenesis. The role of some of these proteins in vibriosis in cod described in this paper can be considered unconventional with respect to their established functions in higher vertebrates. Based on the differential expression of these proteins they are possibly important components of fish defence against bacteria and innate immunity at large. The feasibility of utilizing these proteins/genes as markers of bacterial infection or stress in cod needs to be explored further.
\end{abstract}

Keywords: Comparative proteome, Skin mucosa, Atlantic cod, Vibrio anguillarum, Bath challenge

\footnotetext{
* Correspondence: Monica.Brinchmann@uin.no

Faculty of Biosciences and Aquaculture, University of Nordland, Bodø 8049,

Norway
}

\section{Biomed Central}

(c) 2013 Rajan et al.; licensee BioMed Central Ltd. This is an Open Access article distributed under the terms of the Creative Commons Attribution License (http://creativecommons.org/licenses/by/2.0), which permits unrestricted use, distribution, and reproduction in any medium, provided the original work is properly cited. 


\section{Background}

Fish like Atlantic cod, of the gadoid lineage, are thought to rely extensively on innate immune components $[1,2]$ to ward off infection. Skin mucus is considered to be one of the foremost barriers against pathogen invasion and several mucosal components like lectins, proteases, mucins etc. have been shown to be relevant in the survival of fish [3].

Vibrio anguillarum strains $\mathrm{O} 2 \alpha$ and $\mathrm{O} 2 \beta$ are commonly associated with vibriosis in cod $[4,5]$ and these infections can cause bleeding skin lesions/ulcers and septicemia, resulting in mass mortalities of farmed cod [6]. The ubiquitous distribution of $V$. anguillarum in various marine habitats, their opportunistic nature, and the sporadic recurrences of vibriosis caused by deviating serotypes make the complete eradication of this disease in fish farms infeasible $[7,8]$.

Vibrio infection in mammals is initiated at gut mucosal surfaces [9]. This information spurred investigations on the role of mucosal surfaces in fish, especially in the gut during the progress of vibriosis. Early studies on carp, anally intubated with $V$. anguillarum bacterins, have shown antigen uptake in the second gut segment and subsequent detection of specific antibodies in the gut mucus, skin mucus and serum, indicating a common mucosal response to the antigen [10]. Other studies have shown that establishment of bacteria in the gut is facilitated by chemotaxis, induced by mucosal components such as amino acids, carbohydrate moieties on proteins like high molecular weight mucins, and bile components [11]. Skin is also considered as a potential infection route for $V$. anguillarum, besides gills and gut [7]. Bath challenge experiments have shown that the primary site of attachment and colonization of $V$. anguillarum is the skin and intestine of zebrafish (Danio rerio) [12], and skin and fins of juvenile rainbow trout [13]. $V$. anguillarum virulence is associated with extracellular components like proteases which can cause localized inflammation at the skin surface [6] and it has been shown that epithelial cells in rainbow trout skin can phagocytose $V$. anguillarum [14]. Further, mucosal antibody production has been quantified upon $V$. anguillarum infection [15]. These findings indicate that the pathogen invasion can trigger immune responses in skin and its associated mucosal surface.

Modern techniques like proteomics and transcriptomics can be made use of to study the proteins and genes in the skin mucosa of Atlantic cod afflicted with vibriosis. Such approaches would help us understand host inflammatory responses during disease progression and may pave way for the discovery of vibriosis-related biomarkers. Therefore in the present study we used comparative proteomics to identify differentially expressed proteins from the skin mucus of cod during a natural outbreak of vibriosis.
Further, following a $V$. anguillarum challenge, we examined the transcriptional profiles of the genes, corresponding to the selected proteins, in the skin of cod.

\section{Methods}

\section{V. anguillarum infected Atlantic cod juveniles}

Atlantic cod juveniles hatched (eggs obtained from Cod Farmers ASA, Norway) at Mørkvedbukta Research Station, University of Nordland, Bodø, Norway in early spring 2011 had a natural outbreak of vibriosis during late summer 2011. These were non-vaccinated fish of size 35-50 g, maintained at $7^{\circ} \mathrm{C}$, and fed commercial juvenile feed (Amber Neptun) from Skretting (Stavanger, Norway). Fish from 3 tanks that were diagnosed with vibriosis by Norwegian Veterinary Institute, NorthNorway (Harstad; primary agency for aquaculture disease diagnosis in northern Norway) were used for the first study. The fish in these tanks had experienced stress due to handling of fish while grading and a rise in water temperature $\left(7^{\circ} \mathrm{C}\right.$ to $\left.10^{\circ} \mathrm{C}\right)$. The cumulative mortalities recorded over a period of 15 days in the three tanks were 28,41 and $52 \%$. The fish samples were collected at the end of the recorded mortality period of 15 days starting from first mortality. These fish appeared to be moribund and had bloodshot fins with faint hemorrhages around the fin base. Six fish that were randomly sampled from these tanks to obtain skin mucus were infected with $V$. anguillarum, as confirmed by identifying the bacteria grown on TSA-blood agar with salt [16]. Mucus from six fish of the same stock maintained in separate tanks in a different fish hall, which were confirmed to be not infected, was also sampled. There were no mortalities observed in these control fish group over the same period.

\section{Mucus sample}

Six fish each from infected and non-infected groups were anesthetized in MS-222 and killed by a blow to the head for sampling. Mucus collection was done from normal skin surface avoiding collection of blood along with mucus. Mucus was scraped off with sterile micro slides, transferred into an eppendorf tube and were immediately frozen at $80^{\circ} \mathrm{C}$. All the protocols employed in this study were in accordance with the guidelines of Norwegian Animal Research Authority (FDU, http:// www.fdu.no/fdu/).

\section{Sample preparation and two dimensional gel electrophoresis}

Skin mucus samples were directly solubilized in sample buffer (Bio-Rad, CA, USA) containing $7 \mathrm{M}$ urea, $2 \mathrm{M}$ thiourea, $1 \%(\mathrm{w} / \mathrm{v})$ ASB-14, $40 \mathrm{mM}$ Tris, $0.001 \%$ Bromophenol Blue modified with $0.5 \%$ Bio-Lyte $3 / 10$ ampholyte (Bio-Rad) and $50 \mathrm{mM} \mathrm{DTT}$, vortexed for 15 
min at room temperature (RT) and centrifuged at $20000 \times g$ for $30 \mathrm{~min}$. The supernatant was transferred to a fresh tube and kept on ice. An aliquot of the supernatant solution was dialysed using nanosep omega 3 $\mathrm{kDa}$ cut off columns (Pierce, IL, USA) and the protein quantity in the original solution was measured using Qubit protein assay kit (Invitrogen, Paisley, UK). Hundred $\mu \mathrm{g}$ protein sample was rehydrated in $17 \mathrm{~cm} \mathrm{3-10}$ IPG strips (Bio-Rad) and isoelectric focusing (IEF) was carried out using protean IEF cell (Bio-Rad). After IEF, the strips were immersed in equilibration buffer (6 M urea, 0.375 M Tris-HCl, pH 8.8, 2\% SDS, 20\% glycerol) containing $0.2 \%$ DTT and again in the same buffer containing $0.25 \%$ iodoacetamide. The equilibrated strips were loaded on to $12 \%$ SDS-PAGE gels and run on PROTEAN IIxi system (Bio-Rad). The gels were stained overnight with SYPRO Ruby (Invitrogen) according to supplier's protocol and imaging and documentation was carried out using ChemiDoc ${ }^{\mathrm{TM}}$ XRS imaging system (Bio-Rad). Gel images were analysed using PD Quest Basic software (Bio-Rad). The gel image analysis workflow included spot detection, spot normalization using local regression mode available in the software and finally spot matching and differential expression analysis. Datasets were generated for spots showing significant differential expression using two-tailed Student's t-test for means with $95 \%$ confidence level and $p<0.05$. A fold change threshold of 1.5 was also set to generate a separate dataset. The density values for the spots were then exported to Microsoft Excel (Microsoft, WA, USA) to recalculate the means and find the exact $p$ values as well as creating bar charts.

\section{LC-MSMS analysis}

Eight protein spots showing significant differences and 19 spots that were showing-differential expression trend were excised from preparative SYPRO Ruby stained gels loaded with $500 \mu \mathrm{g}$ protein. The protein spots were in-gel reduced, alkylated and trypsinised as described elsewhere [17] and subjected to LC-MSMS analysis (ESI Quad TOF; Micromass/Waters, MA, USA). Peak lists (pkl) generated by the Protein Lynx Global server software (version 2.1, Micromass/Waters, MA, USA) were adjusted with an internal trypsin standard and further employed for protein database searching.

\section{Bioinformatic analysis}

The peak list files obtained from LC-MSMS analyses were submitted to MASCOT [http://www.matrixscience. com] search engine and searched against NCBInr with the following parameters: maximum one missed cleavage by trypsin, peptide mass tolerance 100 ppm, MS/MS ion tolerance set to $0.1 \mathrm{Da}$, fixed carbamidomethyl modification and variable oxidation modification. Protein hits not satisfying a minimum score of 40 and with a low sequence coverage were further searched against vertebrate EST database, taxonomy Actinopterygii. An interaction network of selected proteins was generated based on their mammalian orthologues (generated through BLASTp searches in NCBI database) using Ingenuity pathway analysis [www.ingenuity.com].

\section{Study on experimentally infected fish}

The bacterial challenge experiment was conducted at the Fish Health Laboratory of the Institute of Marine Research (IMR), Bergen, Norway in cooperation with University of Nordland (UiN), Bodø, Norway. The study was approved by Norwegian Animal Research Authority (FDU; FDU case number 09/112472, approved 22.09.2009) and protocols employed were in accordance with their guidelines. The fish used were juvenile, non vaccinated Atlantic cod procured at $30 \mathrm{~g}$ size (0-yr class) from a commercial hatchery. Prior to the challenge study, groups of 24 fish each of average weight 90 g were introduced into two $500 \mathrm{~L}$ experimental tanks. The fish were fed on a laboratory prepared fishmeal-based feed with the nutrient profiles similar to that of commercial formulations. For performing the bacterial challenge, the water flow into the tanks was stopped for a period of one hour. The fish were then either bath challenged with Vibrio anguillarum (strain H610 from the collection of the Fish Health Group at IMR) or mock challenged with culture media (tryptic soy broth with $1.5 \% \mathrm{NaCl}$ ). The bacterial amount employed for the challenge was $1.6 \times 10^{7} \mathrm{cfu} \mathrm{ml}{ }^{-1}$. Skin and gill samples were collected at $0 \mathrm{~h}$ (4 fish, initial sample) and from both treatment groups (5 fish from each group) at $4 \mathrm{~h}$ and $48 \mathrm{~h}$ post challenge and were immediately snap frozen in liquid nitrogen.

\section{RNA extraction and cDNA synthesis}

RNA was extracted from cod skin and gills using Trizol method as described elsewhere [18]. Total RNA was quality checked on 1\% agarose gels, quantified using Qubit RNA assay (Invitrogen) and treated with gDNA wipe out buffer. cDNA was synthesized from $1 \mu \mathrm{g}$ RNA using QuantiTect Reverse Transcription kit (Qiagen, Hilden, Germany).

\section{Primer design and $\mathrm{qPCR}$}

A tool box of genes identified from the proteome experiment were employed for quantitative real-time PCR. Primers were designed using Primer3 software available online [http://frodo.wi.mit.edu/], after retrieving their full length or partial sequences from Atlantic cod genome database [www.ensembl.org] or NCBI dbEST and they were then evaluated using Netprimer (PREMIER Biosoft, USA). The oligonucleotide primers and their 
attributes are shown in Table 1. Novel full/partial EST sequences were cloned by TA Topo cloning kit (Invitrogen) and sequenced as previously reported [18].

qPCR was performed with StepOne thermocycler (Applied Biosystems (AB), CA, USA). A $10 \mu \mathrm{L}$ PCR mix per reaction was prepared with $1 \mu \mathrm{L}$ of primers $(5 \mathrm{pM}$ each), $5 \mu \mathrm{L}$ of Fast SYBR Green Master Mix (AB) and 4 $\mu \mathrm{L}$ of $25 \mathrm{x}$ diluted cDNA template. The reaction mix was dispensed into 96 well plates and covered with adhesive optical film (AB) and amplification was performed according to the following conditions: holding stage for
$20 \mathrm{sec}$ at $95^{\circ} \mathrm{C}$ for activation of fast Taq DNA polymerase followed by 40 cycles of denaturation at $95^{\circ} \mathrm{C}$ for 3 sec and annealing/extension for $30 \mathrm{sec}$ at $60^{\circ} \mathrm{C}$. Fluorescence data was acquired during the annealing/extension step. The samples were run in duplicates and pooled DNase treated RNA and no template negative controls were also included in the scheme. A 3-fold dilution series from pooled cDNA were included in each plate for each gene and efficiency (E) of PCR reaction for each set of primers was calculated based on standard curve method according to the formula $E=10^{(-1 / \text { slope })}-1^{*} 100$.

Table 1 Oligonucleotide primers employed in this study

\begin{tabular}{|c|c|c|c|c|c|}
\hline Gene name & & Sequence $\left(5^{\prime}-3^{\prime}\right)$ & $\begin{array}{l}\text { Primer } \\
\text { efficiency (\%) }\end{array}$ & Purpose & $\begin{array}{l}\text { Acc. } \\
\text { number }\end{array}$ \\
\hline \multirow[t]{4}{*}{ Profilin2 (Pfn2) } & $F^{1}$ & CCAGCCACTCAATATGTCGT & & cloning & [GenBank:KC460541] \\
\hline & $R^{2}$ & CAAGAACCTGGGAAACACAC & & & \\
\hline & $\mathrm{F}$ & ATCGCAGCACTTTATTCACC & 95.18 & qPCR & \\
\hline & $\mathrm{R}$ & GCGTCCTCCTTGTAGAGGTT & & & \\
\hline \multirow[t]{4}{*}{ Peroxiredoxin 6 (Prdx6) } & $\mathrm{F}$ & TATCGGTGAGACAGGACCAT & & cloning & [GenBank:KC460539] \\
\hline & $\mathrm{R}$ & TGGCGGTTAATTCTAAGTGC & & & \\
\hline & $\mathrm{F}$ & GATGAGATCGACAAGGATGG & 96.99 & qPCR & \\
\hline & $\mathrm{R}$ & TCTATGACCCTCAGCAGCTC & & & \\
\hline \multirow[t]{4}{*}{ Flotillin1 (Flot1) } & $\mathrm{F}$ & TCGCTGAAATAGGTCTCTGG & & cloning & [GenBank:KC460542] \\
\hline & $\mathrm{R}$ & ACTCAGCCTTCTTGGTGTTG & & & \\
\hline & $\mathrm{F}$ & ACCAGGACTACCTCCACTCC & 91.88 & qPCR & \\
\hline & $\mathrm{R}$ & TACTGGGCAGACACCTTCTC & & & \\
\hline \multirow[t]{4}{*}{ Calpain small subunit 1 (Capns1) } & $\mathrm{F}$ & TTCTCTTCTCACCGCAGAAC & & cloning & [GenBank:KC460540] \\
\hline & $\mathrm{R}$ & GACTITICCAGCTCCTCCTC & & & \\
\hline & $\mathrm{F}$ & AACATGGCAACATGGACTIT & 94.05 & qPCR & \\
\hline & $\mathrm{R}$ & TTGACATCAAGGGAGATGGT & & & \\
\hline \multirow[t]{2}{*}{ Beta 2 Tubulin (Tubb2) } & $\mathrm{F}$ & CAGCTACTTCGTGGAATGGA & 94.47 & $\mathrm{qPCR}$ & [GenBank:AAD56401] \\
\hline & $\mathrm{R}$ & CTGTTGCCGATGAAGGTTAC & & & \\
\hline \multirow[t]{4}{*}{ Cold inducible RNA binding protein (Cirbp) } & $\mathrm{F}$ & СTCTTCGGAACTCTCAACCA & & cloning & [GenBank:KC460543] \\
\hline & $\mathrm{R}$ & AATACAGCCAGCCAAGTGAC & & & \\
\hline & $\mathrm{F}$ & GTATGGAAACATCGCCAAAG & 94.17 & qPCR & \\
\hline & $\mathrm{R}$ & CTCGTCGGCATTATCAAACT & & & \\
\hline \multirow[t]{4}{*}{ Glutathione S-transferase omega1(Gsto 1) } & $\mathrm{F}$ & ATTGCGTCTTGGTCATTCAT & & cloning & [GenBank:KC460544] \\
\hline & $\mathrm{R}$ & ACAGGCCATAGTCGTAGTCG & & & \\
\hline & $\mathrm{F}$ & CTGAAACACTTCCTGGATGG & 95.60 & $\mathrm{qPCR}$ & \\
\hline & $\mathrm{R}$ & GCGTGCATGGTTTCTTTAAC & & & \\
\hline \multirow[t]{2}{*}{ Ubiquitin (Ubi) } & $\mathrm{F}$ & GGCCGCAAAGATGCAGAT & 96.10 & $q P C R$ & [GenBank:EX735613] \\
\hline & $\mathrm{R}$ & CTGGGCTCGACCTCAAGAGT & & & \\
\hline \multirow[t]{2}{*}{ Acidic ribosomal protein (Arp) } & $\mathrm{F}$ & TGATCCTCCACGACGATGAG & 95.37 & $q P C R$ & [GenBank:EX741373] \\
\hline & $\mathrm{R}$ & CAGGGCCTTGGCGAAGA & & & \\
\hline \multirow[t]{2}{*}{ Interleukin $1 \beta$ (il1 $\beta$ ) } & $\mathrm{F}$ & GGAGAACACGGACGACCTGA & & $q P C R$ & [GenBank:AJ535730] \\
\hline & $\mathrm{R}$ & CGCACCATGTCACTGTCCTT & & & \\
\hline
\end{tabular}

\footnotetext{
${ }^{1}$ Forward primer.
}

${ }^{2}$ Reverse primer. 
The Ct values obtained for each gene was transformed into relative quantities by setting the highest value to 1 according to the requirement of geNORM software [http://medgen.ugent.be/ jvdesomp/genorm/] to obtain the normalization values for each sample calculated based on the geometric mean of reference genes ubiquitin $(U b i)$ and acidic ribosomal protein $(A r p)$. The normalized values of individual samples were used for statistical analysis.

\section{Statistical analysis}

The statistical analyses of qPCR data were carried out using GraphPad Prism software (GraphPad Software, Inc. CA, USA). The sample sets were tested for normality using Kolmogorov-Smirnov test and data was log transformed where necessary. Transcript profiles for each gene from bacterial challenge group were compared with the respective values from mock challenge control groups, at each time point, using unpaired student's t-test. Zero hour samples that are included in the bar charts as a basal reference point were not included for statistical comparisons.

\section{Results \& discussion}

Proteomic studies on skin mucus from naturally infected fish

Skin mucus is a critical component of piscine immune system. Various antibacterial and inflammatory factors like immunoglobulin, lectins, acute phase proteins, and proteases have been identified in fish mucus [19-21]. We have earlier reported a proteome reference map of Atlantic cod skin mucus, identifying among others innate immune components such as lysozyme, apolipoproteins, galectin-1 and serpins [22]. A separate study showing the presence of antimicrobial components in different tissues including skin mucosa of cod is also available [23]. These studies indicate that the cod skin mucus harbours a significant number of immune relevant proteins. In the present study the skin mucus proteome of healthy cod was compared with that of $V$. anguillarum infected cod. The skin mucus 2D gels showed good resolution and reproducibility (Figure 1). Through gel image analysis, only 8 protein spots were found to be differentially expressed (Figure 2). An additional 19 spots were identified based on high changes observed in individual infected fish (based on variation in spot intensities). There is however, no statistical support for their identification as indicated in Table 2. Nevertheless, this information could be used for further studies, especially targeted transcriptomics or proteomics under natural and bath infection scenarios in fish. The spot details along with accession numbers and other parameters are shown in Table 2.

The rather low number of significantly different protein spots identified in this study could be linked to the possible variation in the progression of $V$. anguillarum infection in individual fish. This could be a disadvantage while analyzing samples from naturally infected fish. Besides, comparative 2D gel analysis has its limitations with regard to high abundant proteins being overrepresented in the gels, which can mask the detection of low abundant inflammatory molecules like interleukins. Also $V$. anguillarum has been shown to have high levels (up to 70 fold) of protease activity in the presence of gastrointestinal mucus [24]. This coupled with the fact that protease inhibitors were not used in the present study might have resulted in degradation of host proteins thereby affecting their detection. Nevertheless, the

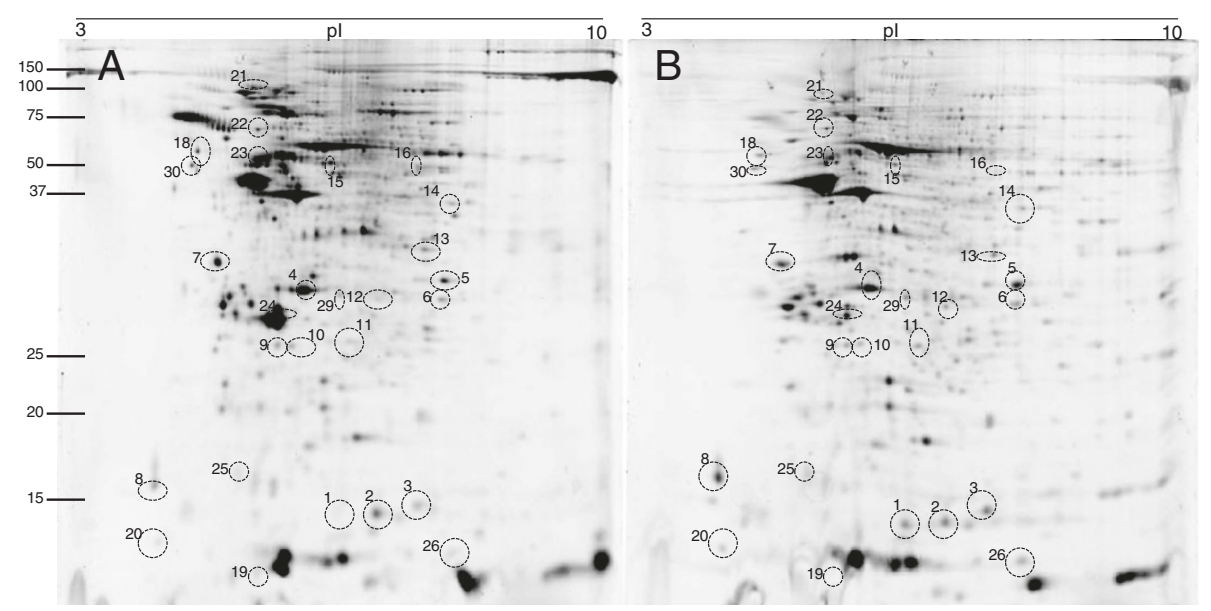

Figure 1 Representative 2D gels of Atlantic cod skin mucus A) Healthy and B) $\boldsymbol{V}$. anguillarum infected. Annotated spots were identified using LC-MSMS. The mucus proteins were isoelectrically focused on 17cm IPG strips (pl 3-10) in first dimension, run on a 12.5\% SDS-PAGE in second dimension and stained with SYPRO Ruby fluorescent dye. Note that the spot numbers correspond to the protein identities outlined in Table 2. $\mathrm{N}=6$. 


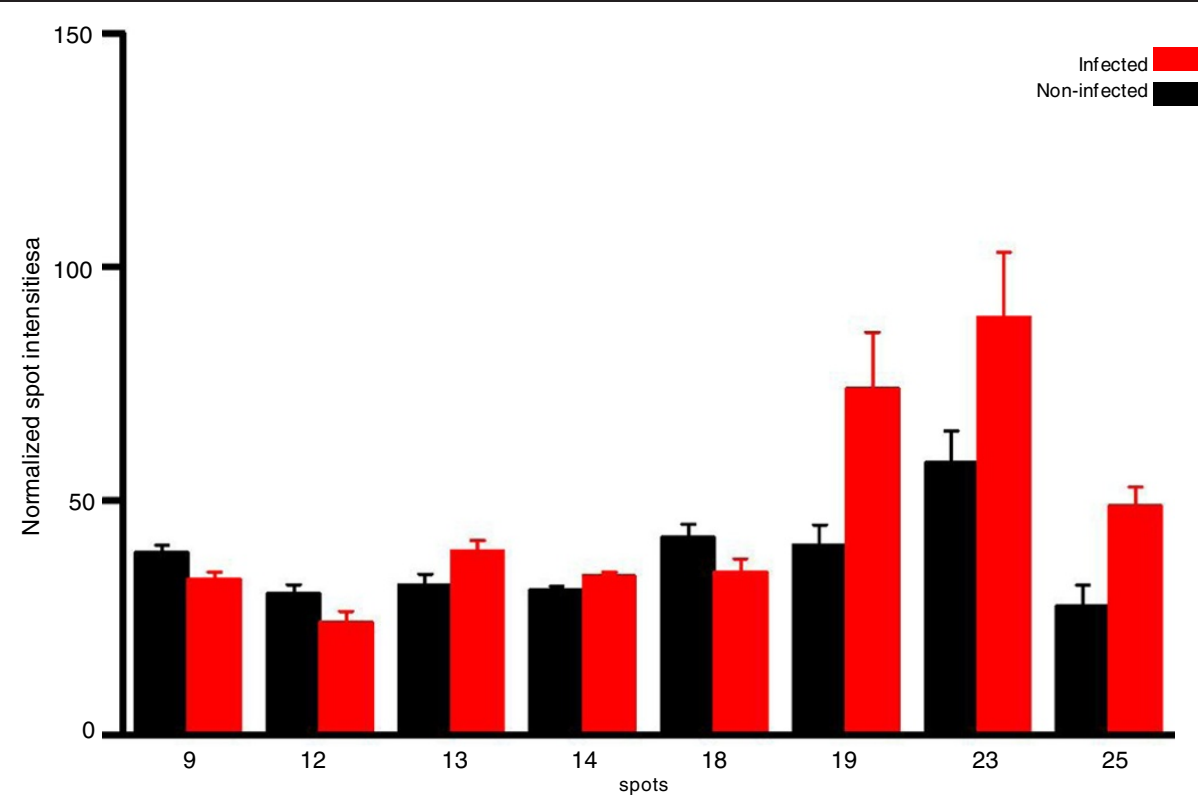

Figure 2 Normalized spot intensities of protein showing statistically significant differences $(p<0.05)$ in healthy vs $V$. anguillarum infected cod skin mucus. Data based on comparative 2D gel analysis employing PD Quest Basic software. $N=6$.

present approach helps in understanding the involvement of protein components during the natural progression of vibriosis in cod.

Proteomic studies to elucidate host responses in fish infected with $V$. anguillarum are limited. To gain a better understanding of the possible role of identified proteins in disease progression and inflammation, a protein-protein interaction network generated by Ingenuity Pathway Analysis (IPA) is shown in Figure 3. The network highlights the interaction of lipoproteins (LDL), mitogen activated protein kinases (ERK1, c-Jun $\mathrm{N}$-terminal kinases (JNK)) and CD3 with proteins identified in the study. The afore mentioned protein families especially the JNKs are activated by stress and inflammatory signals [25] and might have been triggered by a combination of temperature/handling stress the fish had been subjected to, followed by the $V$. anguillarum infection.

Calpain small subunit 1 (CAPNS1) was found to be downregulated in the present study (spot number 9, Figure 2). CAPNS1 is a regulatory component of the calcium dependent cysteine proteases and is ubiquitous in mammalian cells [26]. Calpain mediated proteolysis is limited and calpain usually modifies/alters the substrate proteins instead of bringing about complete degradation [27] indicating its ability to specifically trigger downstream physiological response. There is also evidence that inflammatory cytokines like TNF- $\alpha$ and interleukins can downregulate calpain in cells and tissues [28]. Upregulation of IL- $1 \beta$ and IL- 8 has been observed in the gut of Atlantic cod after intraperitoneal injection with live $V$. anguillarum [29]. Similarly, upregulation of these genes in cod gut were reported after immersion challenge with $V$. anguillarum [30]. Therefore it is likely that inflammatory cytokines induced during $V$. anguillarum infection in cod might have resulted in low levels of CAPNS1 observed in the present study (Figure 2). As $V$. anguillarum infections are characterized by hemorrhagic lesions and wounds in the skin, the downregulation of calpain is logical as the presence of active proteases might lead to exacerbation of disease and irreversible tissue damage [31]. Besides, epidermal lesions that may cause calcium imbalance and disturb membrane integrity can affect the activation of calpain. Human calpain II has been found to be upregulated in psoriasis skin lesions, which are characterized by calcium deficiency [31]. Calpain has been reported in different tissues of fish [32]. Mucosal specific calpains present in higher vertebrates [26] are thought to play important roles in mucosal defense.

Cold inducible RNA binding proteins (CIRBP) are stress proteins with RNA binding domain that can regulate cellular activity under stressful conditions such as hypoxia [33] or during brief periods of osmotic stress [34] in fish. In the present study, Cirbp was significantlyup regulated in infected fish (spot number 25, Figure 2. CIRBP influence the MAPK pathway leading to downstream inflammatory responses as shown in Figure 3.

Malate dehydrogenase 2 (mitochondrial) (MDH2) is a mitochondrial isozyme of malate dehydrogenase that is primarily involved in citric acid cycle [35]. Conditions 
Table 2 Proteins identified in Atlantic cod skin mucus

\begin{tabular}{|c|c|c|c|c|c|c|c|c|}
\hline $\mathbf{N}$ & Protein name (Species) & Acc. no. & $\begin{array}{l}\text { Theoretical } \\
\mathrm{pl} / \mathrm{MW}\end{array}$ & IS & $\begin{array}{l}\text { SC } \\
(\%)\end{array}$ & $\begin{array}{l}\text { Cod EST } \\
\text { Acc. no }\end{array}$ & FCx & $p$ \\
\hline 1 & Profilin-2 (Danio rerio) & NP_958493 & $6.09 / 14.6$ & 474 & 35 & GO379352 & $<1.5$ & $>0.05$ \\
\hline 2 & Profilin-2 (Salmo salar) & ACl66182 & $6.72 / 14.5$ & 393 & 33 & FG312066 & 1.6 & $>0.05$ \\
\hline 3 & Nucleoside diphosphate kinase (G. morhua) & AET05826 & $7.84 / 15.5$ & 623 & 77 & NA & $<1.5$ & $>0.05$ \\
\hline 4 & Inositol monophosphatase 1(Anguilla anguilla) & CBI68709 & $5.35 / 30.6$ & 699 & 35 & GW854257 & $<1.5$ & $>0.05$ \\
\hline 5 & Guanine nucleotide binding protein polypeptide 2 like-1 (S. salar) & $\mathrm{ACH} 70647$ & $7.64 / 28.6$ & 675 & 44 & GW858107 & $<1.5$ & $>0.05$ \\
\hline 6 & Voltage dependent anion selective channel protein 1 (S. salar) & ACl33832 & $8.69 / 30.9$ & 664 & 27 & GW858279 & $<1.5$ & $>0.05$ \\
\hline 7 & Tropomyosin-alpha-4 chain (S. salar) & ACN10541 & $4.57 / 27.9$ & 760 & 39 & FF409290 & $<1.5$ & $>0.05$ \\
\hline 8 & Calmodulin (S. salar) & ACl68592 & $4.09 / 16.7$ & 103 & 19 & NA & $<1.5$ & $>0.05$ \\
\hline 9 & Calpain small subunit-1 (S. salar) & ACl167026 & $5.34 / 24.6$ & 428 & 44 & EX730492 & $<1.5$ & 0.0233 \\
\hline 10 & Calpain small subunit-1 (S. salar) & ACl167026 & $5.34 / 24.6$ & 731 & 42 & GW858828 & $<1.5$ & $>0.05$ \\
\hline 11 & Peroxiredoxin-6 (Scophthalmus maximus) & ADJ57694 & $5.46 / 24.3$ & 306 & 44 & ES239904 & $<1.5$ & $>0.05$ \\
\hline 12 & $\begin{array}{l}\text { PREDICTED: Glutathione S-transferase omega-1 like (Oreochromis } \\
\text { niloticus) }\end{array}$ & XP_003438319 & $6.01 / 27.4$ & 201 & 22 & FCO73610 & $<1.5$ & 0.0409 \\
\hline 13 & Malate dehydrogenase 2-NAD (mitochondrial) (S. salar) & NP_001133198 & $8.15 / 35.8$ & 327 & 19 & NA & 1.52 & 0.0221 \\
\hline 14 & Proteasome (macropain) $26 \mathrm{~S}$ subunit ( S. salar) & ACH85257 & $6.81 / 44.4$ & 246 & 19 & NA & $<1.5$ & 0.0130 \\
\hline 15 & PREDICTED: alpha-enolase-like isoform 1 (S. salar) & XP_003444858 & $5.99 / 47.5$ & 791 & 46 & NA & $<1.5$ & $>0.05$ \\
\hline 16 & Flotillin-1 (Larimichthys crocea) & AEP68103 & & 295 & 17 & NA & $<1.5$ & $>0.05$ \\
\hline 18 & Type II keratin E3 (Oncorhynchus mykiss) & NP_001123458 & $5.32 / 55.3$ & 380 & 20 & GW854186 & $<1.5$ & 0.0413 \\
\hline 19 & 14kDa apolipoprotein (Epinephelus coioides) & ACM41842 & $6.26 / 15.4$ & 249 & 35 & EX189720 & 3.6 & 0.0238 \\
\hline 20 & PREDICTED: similar to ribosomal protein P2 (Taeniopygia guttata) & XP_002199373 & $4.21 / 11.7$ & 327 & 57 & EX174193 & $<1.5$ & $>0.05$ \\
\hline 21 & PREDICTED: endoplasmin-like (O. niloticus) & XP_003443932 & $4.75 / 91.6$ & 339 & 24 & GW849407 & $<1.5$ & $>0.05$ \\
\hline 22 & $\begin{array}{l}\text { Serine/threonine-protein phosphatase } 2 \mathrm{~A} 65 \mathrm{kDa} \text { regulatory } \\
\text { subunit A beta isoform (S. salar) }\end{array}$ & ACN58704 & $4.94 / 65.9$ & 355 & 29 & NA & 2.3 & $>0.05$ \\
\hline 23 & Beta-2-tubulin (G. morhua) & AAD56401 & $4.71 / 50.1$ & 670 & 36 & NA & 2.5 & 0.0419 \\
\hline 24 & Preproapolipoprotein A-1 (G. morhua) & AAU87042 & $5.28 / 29.8$ & 253 & 36 & NA & 2.0 & $>0.05$ \\
\hline 25 & Cold inducible RNA-binding protein (S. salar) & ADM16300 & $5.46 / 16.5$ & 391 & 33 & G0383013 & 2.9 & 0.0029 \\
\hline 26 & FK-506 binding protein 1A (G. morhua) & AEK21706 & $6.71 / 11.8$ & 154 & 32 & NA & $<1.5$ & $>0.05$ \\
\hline 29 & Proteasome activator complex subunit 1 (S. salar) & ACM09791 & $5.54 / 28.62$ & 473 & 18 & GW854458 & $<1.5$ & $>0.05$ \\
\hline 30 & PREDICTED: Calreticulin-like isform 2 (O. niloticus) & XP_003448811 & $4.43 / 47.146$ & 325 & 41 & ES771164 & $<1.5$ & $>0.05$ \\
\hline
\end{tabular}

$\mathrm{N}$-spot number, Acc. No.-Accession number, pl-isoelectric point, $M W$, Molecular weight; IS, lon score; SC, Sequence coverage; $F C$, Fold change; $N A$, Not applicable. Protein spots were identified by LC-MSMS. Proteins either with $p<0.05$ or fold change $>1.5$ or both are in bold letters.

that alter metabolism can result in elevation of mitochondrial enzymes like malate dehydrogenase [36]. An upregulation of MDH2 was noted in the infected cod (spot number 13, Figure 2), possibly triggered by $V$. anguillarum lipopolysacharide (LPS) as shown in a comparative proteome study of Moraxella sp. infected kidney in sea bream (Sparus aurata) [37].

Keratin is a cytoskeletal protein whose primary function is to protect cells from mechanical and non mechanical injuries [38]. Recent reports have also shown that keratin from fish mucus possesses antibacterial activity owing to its pore-forming properties [39]. Keratin turnover is dependent on ubiquitin-proteasome pathway and its expression levels can be altered upon cell injury [40]. There was a downregulation of Keratin II in cod mucus following vibrio infection (spot number 18, Figure 2). Beta-2-tubulins (TUBB2) form integral components of cytoskeleton and are building blocks of microtubules [41]. Tubb2 downregulation has been reported in Chinese white shrimp (Fenneropenaeus chinensis) challenged with $V$. anguillarum [42]. Being an important component of cytoskeletal architecture, different expression levels of tubulin can be presumed to influence the formation of new phagosomes and thus affect phagocytic activity. Whether these changes could be pathogen mediated needs to be investigated. In the present study infected fish showed an increase in TUBB2 in the skin mucus (spot number 23, Figure 2), possibly due to increased expression of Tubb2 in the mucosal cells associated with phagocytic processes. 


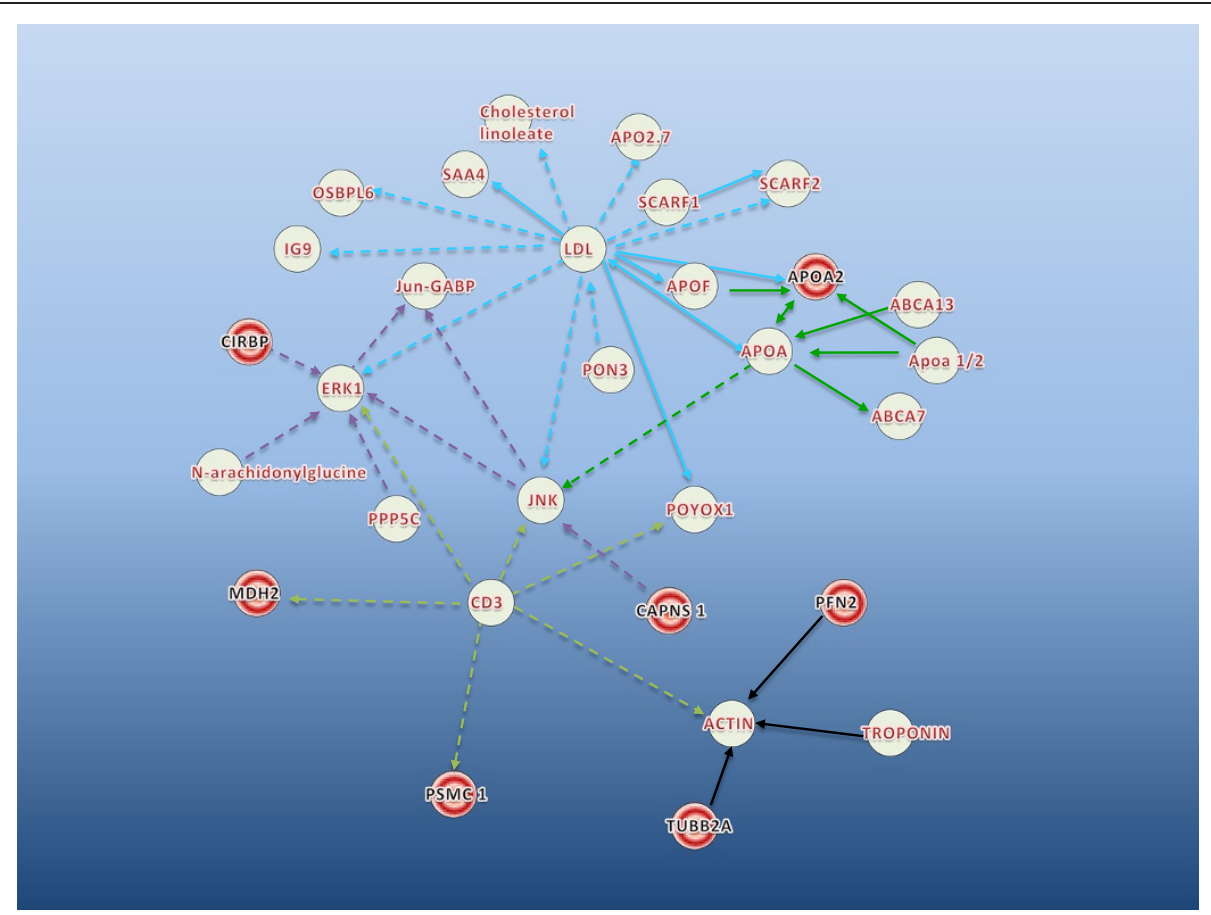

Figure 3 Ingenuity pathway analysis of some key proteins identified in the study. Each gene involved in the pathway is denoted by their ENTREZ gene symbol or in some cases full gene name. The proteins indicated in red circles showed statistically significant $(p<0.05)$ differential expression and/ or fold change $>1.5$ in comparative 2D gel analysis. Grey circles indicate other proteins involved in the pathway. Different coloured arrows are shown to highlight the central molecules involved in the pathway namely; CD3, JNK, ERK1, LDL and APOA. Solid arrows indicate direct protein interactions and dashed arrows indicate indirect protein interactions. Pathway analysis was done based on the mammalian orthologs of the proteins identified in cod mucus.

14-kDa apolipoprotein (apo-14kDa) is a fish specific high density lipoprotein (HDL) orthologous to mammalian apolipoproteinA-II (apoA-II) [43], the expression of which was significantly increased in infected fish (spot number 19, Figure 2). In carp (Cyprinus carpio) it has been shown to have antibacterial effects in vitro [44]. Further, apo- $14 \mathrm{kDa}$ was upregulated in the liver of $V$. anguillarum infected European seabass (Dicentrarchus labrax) [45].

Glutathione-S-transferase omega-1 (GSTO1) is an enzyme involved in biotransformation of compounds including toxic substances and oxidative stress products, transport of ligands, and regulation of signaling pathways [46]. In cod, the Gsto1 transcripts were found in different tissues including skin [47]. In the present study, the protein amount was reduced in infected fish (spot number 12, Figure 2). In Manila clam (Venerupis philippinarum) infected with $V$. anguillarum [48] and Chinese mitten crab (Eriocheir sinensis) injected with Aeromonas hydrophila, an upregulation of novel gst transcripts was noted as early as $6 \mathrm{~h}$ post infection [49]. The upregulation of gst reported in the aforementioned studies could be due to reactive oxygen metabolites induced by the $V$. anguillarum infection as shown in a study where the measurement on enzyme activity complemented the gene expression data [50].

Proteasome 26 subunit is involved in ATP dependent degradation of ubiquitinated proteins, which are instrumental in oxidative stress response and partakes in generating peptide fragments of invading pathogen for antigen presentation [51]. Proteasome expression changes have been reported in response to $V$. anguillarum infection [42] and in Atlantic cod challenged with formalin killed A. salmonicida [52]. In the current study, Proteasome 26S levels were significantly higher in the infected fish (spot number 14, Figure 2).

Other important proteins that exhibited a differential expression trend in this study, including profilin-2, flotilin-1, peroxiredoxin-6, apolipoprotein AI are also important from an immune perspective. The genes corresponding to these proteins could also be considered as potential biomarkers in studies involving $V$. anguillarum infection.

In addition to bacterial infection, Atlantic cod may be susceptible to concurrent or secondary infections with parasites like Trichodina spp [53]. Attempts to identify ectoparasites in skin or gills was not done, hence teoretically such infections may be present and also 
trigger differential expression of certain proteins in the skin of cod.

\section{Gene expression studies on skin from experimentally challenged fish}

In order to understand if the changes in the mucus proteins, arising from natural infection, correspond to the alterations of the respective genes in skin, a controlled bath challenge experiment was performed. The observations were made only during early stages of infection. The $V$. anguillarum $\mathrm{H} 610$ challenge protocol at Institute of Marine Research (IMR), Bergen is robust and well established as reported in different studies [7,54].

Since the proteins were identified through ESTs, the genes had to be cloned. The qPCR expression patterns of selected genes are shown in Figure 4. Significant differential expression of mRNA was detected as early as $4 \mathrm{~h}$ post infection. Capns1 and Gsto1 were upregulated at $4 \mathrm{~h}$ post challenge whereas Flot1 was significantly downregulated compared to the mock challenged controls at $4 \mathrm{~h}$ and $48 \mathrm{~h}$ post infection (Figure 4). Expression of Cirbp and Tubb2 were significantly downregulated $48 \mathrm{~h}$ post infection (Figure 4). There was no significant difference in the expression patterns of $P f n 2$ and $\operatorname{Prdx} 6$ (Figure 4). To confirm infection after experimental bacterial challenge, interleukin-1 $\beta(i l 1 \beta)$ transcripts were quantified in the skin and gill tissue of the infected fish. The ill $\beta$ mRNA levels were found to be significantly upregulated in gills at $48 \mathrm{~h}$ post bath challenge compared to the control [see Additional file 1]. $i l 1 \beta$ transcripts of skin showed no changes at the two time points (data not shown).

The gene expression data and proteomic data need not always show a one to one correspondence [55]. Nevertheless, as observed in the qPCR study these gene transcripts show a differential expression during the early stages of $V$. anguillarum infection and it can be surmised that they may play important role in the progression of vibriosis in cod. Fish skin has been seldom targeted for gene expression studies, in challenge

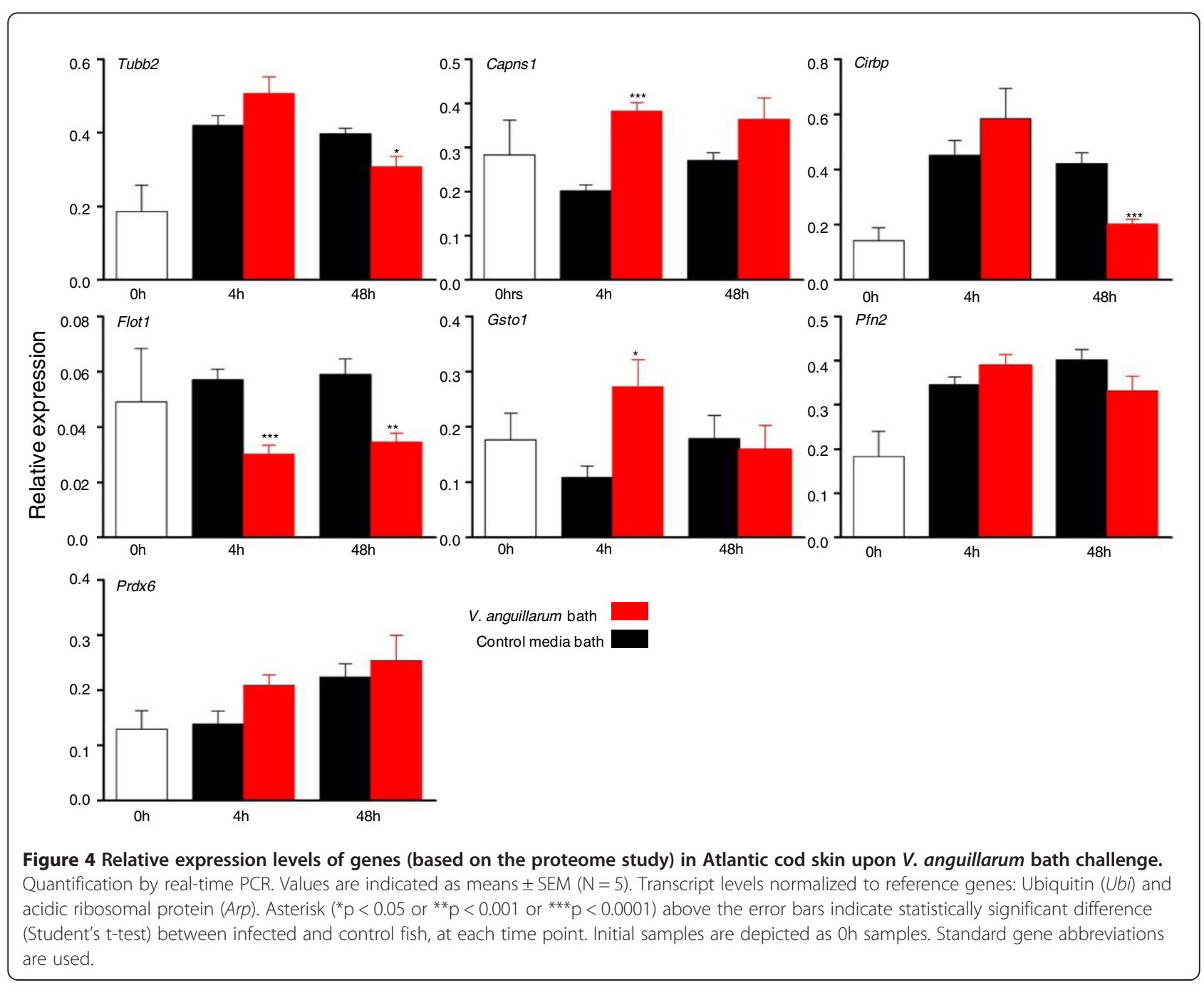


experiments and infection scenarios, as most of them focused on systemic immune-relevant organs like spleen and head kidney. The expression of key immune genes in skin has been explored primarily in the case of ectoparasite infections [56]. A recent report on the expression of key immune relevant genes in naive Atlantic cod skin [57] taken together with the present study demonstrates the role of immune relevant components in the skin mucus/skin of cod both at protein and transcript level during bacterial infection.

Thus, through the proteomic approach we were able to identify differentially regulated proteins in skin mucus that might be relevant targets for gene expression studies as evident from this study. Going further, the ultimate objective of this study is to utilize the mucosal proteins as biomarkers for early assessment of fish health status, aimed at controlling bacterial diseases including vibriosis.

\section{Conclusions}

We identified a group of proteins, of which the involvement of some can be considered novel in $V$. anguillarum infection of cod. More importantly, these proteins are shown to be closely associated with key pathways that mount an immune response in the host. The early induction of mRNA transcripts of some of the selected genes also points towards their involvement along with other acute phase proteins as primary orchestrators in the fish mucosal immunity against bacterial infection.

\section{Additional file}

\section{Additional file 1: Relative expression of interleukin-1 $\beta$ (il1 $\beta$ ) in gill} tissue of Atlantic cod bath challenged with Vibrio anguillarum. Quantification of il/ $\beta$ mRNA level by real-time PCR at $4 \mathrm{~h}$ and $48 \mathrm{~h}$ post bath challenge. Values are indicated as means \pm SEM $(N=5)$. Transcript levels normalized to reference genes: Ubiquitin (Ubi) and acidic ribosomal protein $\left(\right.$ Arp). Asterisk ( $\left.{ }^{*} p<0.05\right)$ above the error bars indicate statistically significant difference (Student's t-test) between infected and control fish, at each time point.

\section{Competing interests}

The authors declare that they have no competing interests.

\section{Authors' contributions}

Conceived and designed the experiments: BR, VK and MFB. Performed the experiments: BR and L. Analyzed the data: BR and MFB. Wrote the paper: BR, VK and MFB. All authors read and approved the final manuscript.

\section{Acknowledgements}

The present study was supported by the projects 'Preventive Health Care of Farmed Fish' (176528) and 'Mucosal Immune System of Atlantic CodCreating a knowledge Base' (184703) from the Research Council of Norway, granted to VK. Dr. Øivind Bergh is thanked for his contributions in conducting the challenge experiments at Bergen. The authors thank Hilde Ribe and Kathrine Klippenberg, University of Nordland, Hari Rudra, Ann Cathrine Einen and Rolf Hetelid Olsen, Institute of Marine Research for their technical support in conducting the bacterial challenge experiment.
Received: 26 January 2013 Accepted: 8 May 2013

Published: 14 May 2013

\section{References}

1. Star B, Nederbragt AJ, Jentoft S, Grimholt U, Malmstrom M, Gregers TF, Rounge TB, Paulsen J, Solbakken MH, Sharma A, et al: The genome sequence of Atlantic cod reveals a unique immune system. Nature 2011, 477:207-210.

2. Pilstrom L, Warr GW, Stromberg S: Why is the antibody response of Atlantic cod so poor? The search for a genetic explanation. Fish Sci 2005, 71:961-971.

3. Esteban MA: An overview of the immunological defenses in fish skin. ISRN Immunol 2012. doi:10.5402/2012/853470.

4. Larsen $J \mathrm{~L}$, Pedersen $\mathrm{K}$, Dalsgaard I: Vibrio anguillarum serovars associated with vibriosis in fish. J Fish Dis 1994, 17:259-267.

5. Pedersen K, Grisez L, Houdt R, Tiainen T, Ollevier F, Larsen JL: Extended serotyping scheme for Vibrio anguillarum with the definition and characterization of seven provisional O-serogroups. Curr Microbiol 1999, 38:183-189.

6. Frans I, Michiels CW, Bossier P, Willems KA, Lievens B, Rediers H: Vibrio anguillarum as a fish pathogen: virulence factors, diagnosis and prevention. J Fish Dis 2011, 34:643-661.

7. Engelsen AR, Sandlund N, Fiksdal IU, Bergh O: Immunohistochemistry of Atlantic cod larvae Gadus morhua experimentally challenged with Vibrio anguillarum. Dis Aquat Organ 2008, 80:13-20.

8. Mikkelsen $H$, Lund V, Larsen $R$, Seppola M: Vibriosis vaccines based on various sero-subgroups of Vibrio anguillarum $\mathrm{O} 2$ induce specific protection in Atlantic cod (Gadus morhua L.) juveniles. Fish Shellfish Immunol 2011, 30:330-339

9. Harris JB, LaRocque RC, Qadri F, Ryan ET, Calderwood SB: Cholera. Lancet 2012, 379:2466-2476.

10. Rombout JWHM, Blok L, Lamers CHJ, Egberts E: Immunization of carp (Cyprinus carpio) with a Vibrio anguillarum bacterin: Indications for a common mucosal immune system. Dev Comp Immunol 1986, 10:341-351.

11. OToole R, Lundberg S, Fredriksson S-Å, Jansson A, Nilsson B, Wolf-Watz H: The chemotactic response of Vibrio anguillarum to fish intestinal mucus is mediated by a combination of multiple mucus components. J Bacteriol 1999, 181:4308-4317.

12. O'Toole R, von Hofsten J, Rosqvist R, Olsson P-E, Wolf-Watz H: Visualisation of Zebrafish infection by GFP-labelled Vibrio anguillarum. Microb Pathog 2004, 37:41-46.

13. Spanggaard B, Huber I, Nielsen J, Nielsen T, Gram L: Proliferation and location of Vibrio anguillarum during infection of rainbow trout, Oncorhynchus mykiss (Walbaum). J Fish Dis 2000, 23:423-427.

14. Lindell K, Fahlgren A, Hjerde E, Willassen N-P, Fällman M, Milton DL: Lipopolysaccharide O-antigen prevents phagocytosis of Vibrio anguillarum by rainbow trout (Oncorhynchus mykiss) skin epithelial cells. PLoS One 2012, 7:e37678.

15. Vervarcke S, Ollevier F, Kinget R, Michoel A: Mucosal response in African catfish after administration of Vibrio anguillarum $\mathrm{O} 2$ antigens via different routes. Fish Shellfish Immunol 2005, 18:125-133.

16. Rock JL, Nelson DR: Identification and characterization of a hemolysin gene cluster in Vibrio anguillarum. Infect Immun 2006, 74:2777-2786.

17. Øverbye A, Brinchmann MF, Seglen PO: Proteomic analysis of membraneassociated proteins from rat liver autophagosomes. Autophagy 2007, 3:300-322.

18. Fernandes JMO, Ruangsri J, Kiron V: Atlantic cod piscidin and its diversification through positive selection. PLoS One 2010, 5:e9501.

19. Subramanian S, Mackinnon SL, Ross NW: A comparative study on innate immune parameters in the epidermal mucus of various fish species Comp Biochem Physiol B 2007, 148:256-263.

20. Shephard KL: Functions for fish mucus. Rev Fish Biol Fish 1994, 4:401-429.

21. Suzuki Y, Tasumi S, Tsutsui S, Okamoto M, Suetake H: Molecular diversity of skin mucus lectins in fish. Comp Biochem Physiol B 2003, 136:723-730.

22. Rajan B, Fernandes JMO, Caipang CMA, Kiron V, Rombout JHWM, Brinchmann MF: Proteome reference map of the skin mucus of Atlantic cod (Gadus morhua) revealing immune competent molecules. Fish Shellfish Immunol 2011, 31:224-231.

23. Ruangsri J, Fernandes JMO, Brinchmann M, Kiron V: Antimicrobial activity in the tissues of Atlantic cod (Gadus morhua L.). Fish Shellfish Immunol 2010, 28:879-886. 
24. Denkin SM, Nelson DR: Induction of protease activity in Vibrio anguillarum by gastrointestinal mucus. Appl Environ Microbiol 1999, 65:3555-3560.

25. Vlahopoulos S, Zoumpourlis VC: JNK: A key modulator of intracellular signaling. Biochemistry (Mosc) 2004, 69:844-854.

26. Sorimachi H, Hata S, Ono Y: Calpain chronicle-an enzyme family under multidisciplinary characterization. Proc Jpn Acad Ser B Phys Biol Sci 2011 87:287-327

27. Saido TC, Sorimachi H, Suzuki K: Calpain: C: new perspectives in molecular diversity and physiological-pathological involvement. FASEB J 1994, 8:814-822.

28. Ishikawa H, Nakagawa Y, Shimizu K, Nishihara H, Matsusue Y, Nakamura T: Inflammatory cytokines induced down-regulation of $\mathrm{m}$-calpain mRNA expression in fibroblastic synoviocytes from patients with osteoarthritis and rheumatoid arthritis. Biochem Biophys Res Commun 1999, 266:341-346.

29. Inami M: The immune system of Atlantic cod: with emphasis on intestinal immunology. University of Tromsø, Faculty of Biosciences, Fisheries and Economics: PhD thesis; 2011.

30. Lokesh J, Fernandes JMO, Korsnes K, Bergh $\varnothing$, Brinchmann MF, Kiron V: Transcriptional regulation of cytokines in the intestine of Atlantic cod fed yeast derived mannan oligosaccharide or $\beta$-glucan and challenged with Vibrio anguillarum. Fish Shellfish Immunol 2012, 33:626-631.

31. Matsushita Y, Shimada Y, Kawara S, Takehara K, Sato S: Autoantibodies directed against the protease inhibitor calpastatin in psoriasis. Clin Exp Immunol 2005, 139:355-362.

32. Salem M, Nath J, Killefer J: Cloning of the calpain regulatory subunit CDNA from fish reveals a divergent domain-V. Anim Biotechnol 2004, 15:145-157.

33. Wellmann S, Bührer C, Moderegger E, Zelmer A, Kirschner R, Koehne $P$, Fujita J, Seeger K: Oxygen-regulated expression of the RNA-binding proteins RBM3 and CIRP by a HIF-1-independent mechanism. J Cell Sci 2004, 117:1785-1794.

34. Pan F, Zarate J, Choudhury A, Rupprecht R, Bradley TM: Osmotic stress of salmon stimulates upregulation of a cold inducible RNA binding protein (CIRP) similar to that of mammals and amphibians. Biochimie 2004, 86:451-461.

35. Minárik P, Tomásková N, Kollárová M, Antalík M: Malate dehydrogenasesstructure and function. Gen Physiol Biophys 2002, 21:257-265.

36. Cripps RA, Reish DJ: The effect of environmental stress on the activity of malate dehydrogenase and lactate dehydrogenase in Neanthes arenaceodentata (Annelida: Polychaeta). Comp Biochem Physiol B 1973, 46:123-133

37. Addis M, Cappuccinelli R, Tedde V, Pagnozzi D, Viale I, Meloni M, Salati F, Roggio T, Uzzau S: Influence of Moraxella sp. colonization on the kidney proteome of farmed gilthead sea breams (Sparus aurata L.). Proteome Sci 2010, 8:50.

38. Coulombe PA, Omary MB: 'Hard' and 'soft' principles defining the structure, function and regulation of keratin intermediate filaments. Curr Opin Cell Biol 2002, 14:110-122.

39. Molle V, Campagna S, Bessin Y, Ebran N, Saint N, Molle G: First evidence of the pore-forming properties of a keratin from skin mucus of rainbow trout (Oncorhynchus mykiss, formerly Salmo gairdneri). Biochem J 2008, 411:33-40.

40. Rogel MR, Jaitovich A, Ridge KM: The role of the ubiquitin proteasome pathway in keratin intermediate filament protein degradation. Proc Am Thorac Soc 2010, 7:71-76.

41. Hammond JW, Cai D, Verhey KJ: Tubulin modifications and their cellular functions. Curr Opin Cell Biol 2008, 20:71-76.

42. Zhang J, Li F, Jiang H, Yu Y, Liu C, Li S, Wang B, Xiang J: Proteomic analysis of differentially expressed proteins in lymphoid organ of Fenneropenaeus chinensis response to Vibrio anguillarum stimulation. Fish Shellfish Immunol 2010, 29:186-194.

43. Choudhury M, Yamada S, Komatsu M, Kishimura H, Ando S: Homologue of mammalian apolipoprotein A-II in non-mammalian vertebrates. Acta Biochim Biophys Sin 2009, 41:370-378.

44. Concha MI, Smith VJ, Castro K, Bastías A, Romero A, Amthauer RJ: Apolipoproteins $A-I$ and $A-I I$ are potentially important effectors of innate immunity in the teleost fish Cyprinus carpio. Eur J Biochem 2004 271:2984-2990.

45. Sarropoulou E, Sepulcre P, Poisa-Beiro L, Mulero V, Meseguer J, Figueras A, Novoa B, Terzoglou V, Reinhardt R, Magoulas A, et al: Profiling of infection specific mRNA transcripts of the European seabass Dicentrarchus labrax. BMC Genomics 2009, 10:157.
46. Burmeister C, Lüersen K, Heinick A, Hussein A, Domagalski M, Walter RD, Liebau E: Oxidative stress in Caenorhabditis elegans: protective effects of the Omega class glutathione transferase (GSTO-1). FASEB J 2008, 22:343-354.

47. Olsvik PA, Nordtug T, Altin D, Lie KK, Overrein I, Hansen BH: Transcriptional effects on glutathione S-transferases in first feeding Atlantic cod (Gadus morhua) larvae exposed to crude oil. Chemosphere 2010, 79:905-913.

48. Li C, Su X, Li Y, Li T, Sun C, Zhou T, Liu H: Two classes of glutathione Stransferase genes with different response profiles to bacterial challenge in Venerupis philippinarum. Fish Shellfish Immunol 2012, 32:219-222.

49. Zhao D, Chen L, Qin C, Zhang H, Wu P, Zhang F: A delta-class glutathione transferase from the Chinese mitten crab Eriocheir sinensis: cDNA cloning, characterization and mRNA expression. Fish Shellfish Immunol 2010, 29:698-703.

50. Canesi L, Barmo C, Fabbri R, Ciacci C, Vergani L, Roch P, Gallo G: Effects of vibrio challenge on digestive gland biomarkers and antioxidant gene expression in Mytilus galloprovincialis. Comp Biochem Physiol C 2010, 152:399-406.

51. Kloetzel P-M, Ossendorp F: Proteasome and peptidase function in MHCclass-I-mediated antigen presentation. Curr Opin Immunol 2004, 16:76-81.

52. Feng CY, Johnson SC, Hori TS, Rise M, Hall JR, Gamperl AK, Hubert S, Kimball J, Bowman S, Rise ML: Identification and analysis of differentially expressed genes in immune tissues of Atlantic cod stimulated with formalin-killed, atypical Aeromonas salmonicida. Physiol Genomics 2009, 37:149-163.

53. Bricknell IR, Bron JE, Bowden TJ: Diseases of gadoid fish in cultivation: a review. ICES J Mar Sci 2006, 63:253-266.

54. Samuelsen $\mathrm{OB}$, Bergh $\varnothing$ : Efficacy of orally administered florfenicol and oxolinic acid for the treatment of vibriosis in cod (Gadus morhua). Aquaculture 2004, 235:27-35.

55. Gygi SP, Rochon Y, Franza BR, Aebersold R: Correlation between protein and mRNA abundance in yeast. Mol Cell Biol 1999, 19:1720-1730.

56. Sigh J, Lindenstrøm T, Buchmann K: Expression of pro-inflammatory cytokines in rainbow trout (Oncorhynchus mykiss) during an infection with Ichthyophthirius multifiliis. Fish Shellfish Immunol 2004, 17:75-86.

57. Caipang CMA, Lazado CC, Brinchmann MF, Rombout JHWM, Kiron V: Differential expression of immune and stress genes in the skin of Atlantic cod (Gadus morhua). Comp Biochem Physiol D 2011, 6:158-162.

\section{doi:10.1186/1746-6148-9-103}

Cite this article as: Rajan et al:: Differentially expressed proteins in the skin mucus of Atlantic cod (Gadus morhua) upon natural infection with Vibrio anguillarum. BMC Veterinary Research 2013 9:103.

\section{Submit your next manuscript to BioMed Central and take full advantage of:}

- Convenient online submission

- Thorough peer review

- No space constraints or color figure charges

- Immediate publication on acceptance

- Inclusion in PubMed, CAS, Scopus and Google Scholar

- Research which is freely available for redistribution 